University of South Carolina

Scholar Commons

$5-14-2014$

\title{
A Novel Intermediate-Temperature All Ceramic Iron-Air Redox Battery: The Effect of Current Density and Cycle Duration
}

Xuan Zhao

Xue Li

Yunhui Gong

Nansheng Xu

Kevin Huang

University of South Carolina - Columbia, huang46@cec.sc.edu

Follow this and additional works at: https://scholarcommons.sc.edu/emec_facpub

Part of the Mechanical Engineering Commons

\section{Publication Info}

Published in RSC Advances, Volume 4, Issue 43, 2014, pages 22621-22624.

CRSC Advances (2014), Royal Society of Chemistry.

This article cannot be redistributed of further made available.

This article was first published by the Royal Society of Chemistry and can be found at http://dx.doi.org/ $10.1039 / \mathrm{c} 4 \mathrm{ra02768j}$

Zhao, X., Li, X., Gong, Y., Xu, N. \& Huang, K. (2014). A Novel Intermediate-Temperature All Ceramic Iron-Air Redox Battery: The Effect of Current Density and Cycle Duration. RSC Advances, 4 (43), 22621-22624. http://dx.doi.org/10.1039/C4RA02768J 
Cite this: RSC Adv., 2014, 4, 22621

Received 28th March 2014

Accepted 14th May 2014

DOI: $10.1039 / \mathrm{c} 4 \mathrm{ra02768j}$

www.rsc.org/advances

\section{A novel intermediate-temperature all ceramic iron-air redox battery: the effect of current density and cycle duration}

\author{
Xuan Zhao, Xue Li, Yunhui Gong, Nansheng Xu and Kevin Huang* \\ We here report the energy storage characteristics of a new all ceramic iron-air redox battery comprising of \\ a reversible solid oxide fuel cell as the charger/discharger and a $\mathrm{Fe}-\mathrm{FeO}_{x}$ redox couple as the chemical \\ storage bed. The effects of current density and cycle duration on specific energy and round trip \\ efficiency of the new battery have been systematically studied at $650{ }^{\circ} \mathrm{C}$ and $550{ }^{\circ} \mathrm{C}$. The results \\ explicitly show that current density is the most influential variable on the performance, signifying the \\ importance of improving electrochemical performance of the reversible solid oxide fuel cell.
}

\section{Introduction}

Metal-air batteries are a class of promising electrical energy storage systems with high energy density and inexhaustible, storage-free source of cathode oxidant (air). However, commercial development of conventional liquid-electrolyte based metal-air batteries relying on $\mathrm{A}^{+}$(e.g., $\mathrm{A}=\mathrm{Li}, \mathrm{Na}$ ) and/or $\mathrm{OH}^{-}$conduction has been severely hampered by the irreversibility, fast capacity decay and electrode deformation, to name just a few reasons. Most of these problems are directly related to the chemical interactions between solid electrodes and liquid electrolytes and blockage of reactants' access to the reactive sites.

To cope with these problems, we have recently demonstrated a new type of metal-air redox battery comprising of all ceramic solid-oxide components: solid oxide metal-air redox batteries (SOMARBs). ${ }^{1-10}$ The new battery is centered on solid-state oxideion transport chemistry, utilizing a reversible solid oxide fuel cell (RSOFC) as the electrical charger/discharger and a metal/ metal-oxide mixture as the chemical energy storage bed. Similar works have also been reported by other group. ${ }^{11-19}$ The working principle of the SOMARB is best illustrated by the chemistry of iron-air shown in Fig. 1; the free-standing $\mathrm{Fe}-\mathrm{FeO}_{x}$ chemical bed is situated inside the fuel-electrode chamber where an oxygen shuttle $\mathrm{H}_{2}-\mathrm{H}_{2} \mathrm{O}$ is present to transport oxygen between RSOFC and chemical bed. Comparing with the conventional liquid $\mathrm{A}^{+}$or $\mathrm{OH}^{-}$transport based metal-air batteries, the solidstate $\mathrm{O}^{2-}$-transport chemistry enables high rate of charge transfer and ensures minimal chemical reactions between electrolyte and electrodes.

While the basic energy storage characteristics, e.g. specific energy (SE) and cycleability, of a number of metal-air

Department of Mechanical Engineering, University of South Carolina, Columbia, SC29201, USA. E-mail: kevin.huang@sc.edu chemistries have been previously demonstrated in SOMARB for preselected conditions, the effects of operating current density and cycle duration on specific energy and round trip efficiency (RTE) have not been systematically studied even though these two parameters are critically important to the design and operation of a practical SOMARB. This study is aimed to fill this gap by systematically investigating the effects of these two parameters for a solid oxide iron-air redox battery.

\section{Experimental procedures}

Battery materials and assembly

The battery for the tests were assembled in a planar button cell configuration as described previously. ${ }^{2}$ The RSOFC was comprised of a $200 \mu \mathrm{m}$ thick $\mathrm{La}_{0.8} \mathrm{Sr}_{0.2} \mathrm{Ga}_{0.83} \mathrm{Mg}_{0.17} \mathrm{O}_{3-\delta}$ (LSGM) electrolyte membrane prepared by tape casting and nanostructured $\mathrm{Sm}_{0.6} \mathrm{Sr}_{0.4} \mathrm{CoO}_{3-\delta}$ (SSC) cathode and $\mathrm{Ni}$ anode prepared by infiltration method. ${ }^{7,8}$ The active electrode area was $1.3 \mathrm{~cm}^{2}$. The nanostructured $\mathrm{Fe}-\mathrm{FeO}_{x}$ redox couple material was synthesized from a carbothermic reaction; the details about this synthesis can be found in ref. 8. The iron loading has been consistently kept as 0.7 grams for the tests carried out throughout the study.

\section{Battery testing}

At the beginning of each test, the battery cell was first heated up in a mixture of $5 \% \mathrm{H}_{2}$ and $\mathrm{N}_{2}$. Once reaching the melting temperature of the sealing glass at $650{ }^{\circ} \mathrm{C}$, the $5 \% \mathrm{H}_{2}-\mathrm{N}_{2}$ gas was switched to a pure $\mathrm{H}_{2}$ humidified with $3 \% \mathrm{H}_{2} \mathrm{O}$. After converting iron oxide into iron, the inlet and outlet of $\mathrm{H}_{2}$ flow were closed off, making the fuel-electrode a closed chamber. To create the $\mathrm{Fe}-\mathrm{FeO}_{x}$ redox couple from pure $\mathrm{Fe}$, a small discharge current of $10 \mathrm{~mA} \mathrm{~cm}^{-2}$ was applied by the RSOFC to convert $\mathrm{H}_{2}$ into $\mathrm{H}_{2} \mathrm{O}$, and further $\mathrm{Fe}$ into $\mathrm{FeO}_{x}$. To ensure the attainment of 


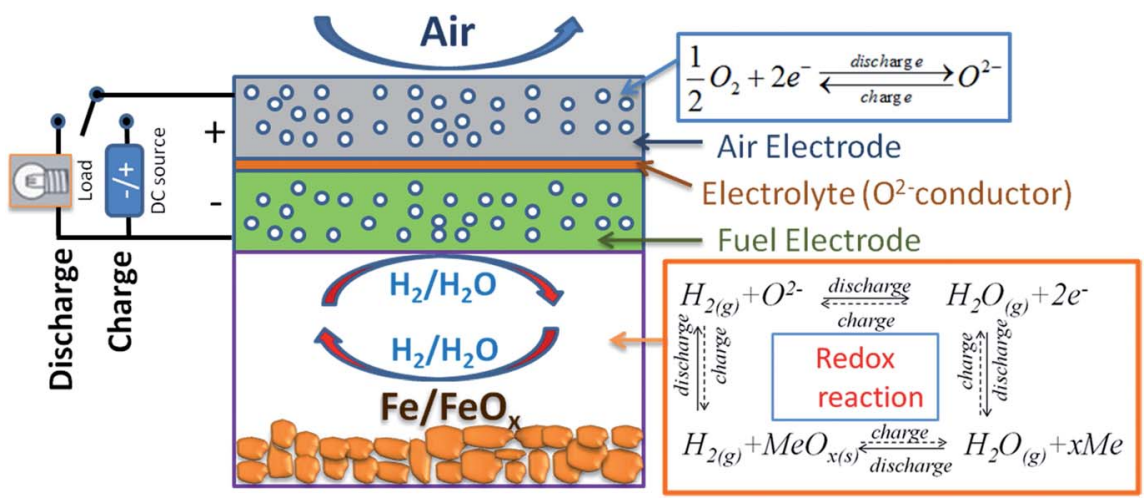

Fig. 1 Schematic of the working principle of the all ceramic solid oxide iron-air redox battery.

$\mathrm{Fe}-\mathrm{FeO}_{x}$ equilibrium without over-consuming the active $\mathrm{Fe}$, EMF of the RSOFC was closely monitored during the electrochemical oxidation by intermittently switching between the discharging and OCV states. As soon as the EMF reached the theoretical value, an indication of attainment of $\mathrm{Fe}-\mathrm{FeO}_{x}$ equilibrium, the electrochemical oxidation was stopped, and the system was ready for the charge-discharge cycles. It is worth mentioning that the equilibrium redox couple is $\mathrm{Fe}-\mathrm{FeO}$ for $650{ }^{\circ} \mathrm{C}$ and $\mathrm{Fe}-\mathrm{Fe}_{3} \mathrm{O}_{4}$ for $550^{\circ} \mathrm{C}$; the corresponding EMFs of the batteries are 1.03 and 1.07 volt, respectively.

Before each battery's performance evaluation, the battery was first characterized by DC polarization and AC impedance spectroscopy to establish the performance baseline such as $V-I$ and $P-I$ curves for RSOFC in the temperature range of 550$650{ }^{\circ} \mathrm{C}$. The typical impedance spectrum was collected in the frequency range of $0.01-6.3 \times 10^{5} \mathrm{~Hz}$ and an $\mathrm{AC}$ perturbation

Table 1 Current density and cycle duration used in the study ${ }^{a}$

\begin{tabular}{llllll}
\hline$T^{\circ} \mathrm{C}$ & Constants & \multicolumn{4}{c}{ Independent variables $\left(t\right.$ in min; $j$ in $\left.\mathrm{mA} \mathrm{cm}^{-2}\right)$} \\
\hline 650 & $j=25$ & $t=10$ & $t=20$ & $t=30$ & $t=40$ \\
& $t=10$ & $j=25$ & $j=50$ & $j=75$ & $j=100$ \\
550 & $j=10$ & $t=10$ & $t=20$ & $t=30$ & $t=40$ \\
& $t=10$ & $j=10$ & $j=20$ & $j=30$ & $j=40$
\end{tabular}

${ }^{a} j$ - current density; $t$ - cycle duration for single discharge or charge cycle. amplitude of $10 \mathrm{mV}$. As a standard practice in electrochemical impedance spectroscopy, the area-specific ohmic and polarization resistances were extracted from the spectrum at high and low frequency region, respectively. These initial performances were used to compare with those post-cycled batteries to discern performance degradation.

To examine the effects of current density and cycle duration on battery's SE and round-trip efficiency (RTE), a testing matrix shown in Table 1 was created. The execution of this testing matrix was carried out on a single-cycle basis to minimize uncontrollable variables such as "aging". After each cycle $\mathrm{H}_{2}-$ $3 \% \mathrm{H}_{2} \mathrm{O}$ was re-introduced into the fuel electrode chamber before the next test. A Solartron 1260/1287 Electrochemical System was employed to characterize the electrical performance of the battery under various operating conditions with software modules such as impedance, OCV- $t$ and galvanic cycles.

\section{Results and discussion}

\section{Fuel cell performance of the battery}

The fuel cell performance of the RSOFC used by the battery is represented in Fig. 2 by AC impedance spectrum and $V-I$ (or $P-I$ ) characteristic measured at 550 and $650{ }^{\circ} \mathrm{C}$ with air and $\mathrm{H}_{2}-3 \%$ $\mathrm{H}_{2} \mathrm{O}$ as the oxidant and fuel, respectively. The total cell resistance increases from $3.92 \Omega \mathrm{cm}^{2}$ at $650{ }^{\circ} \mathrm{C}$ to $10.55 \Omega \mathrm{cm}^{2}$ at $550{ }^{\circ} \mathrm{C}$. The corresponding peak power density decreases from $176 \mathrm{~mW} \mathrm{~cm}^{-2}$ (a) $280 \mathrm{~mA} \mathrm{~cm}{ }^{-2}$ at $650{ }^{\circ} \mathrm{C}$ to $64 \mathrm{~mW} \mathrm{~cm}^{-2}$ (a)
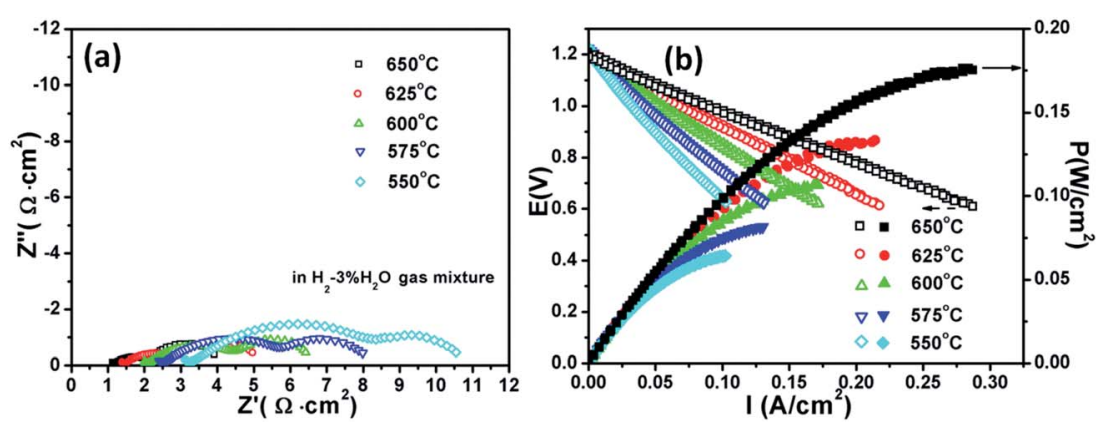

Fig. 2 Fuel cell performance of RSOFC tested in $\mathrm{H}_{2}-3 \% \mathrm{H}_{2} \mathrm{O}$ gas mixture; (a) impedance spectra and (b) $V-I \& P-I$ characteristics measured under different temperatures. 

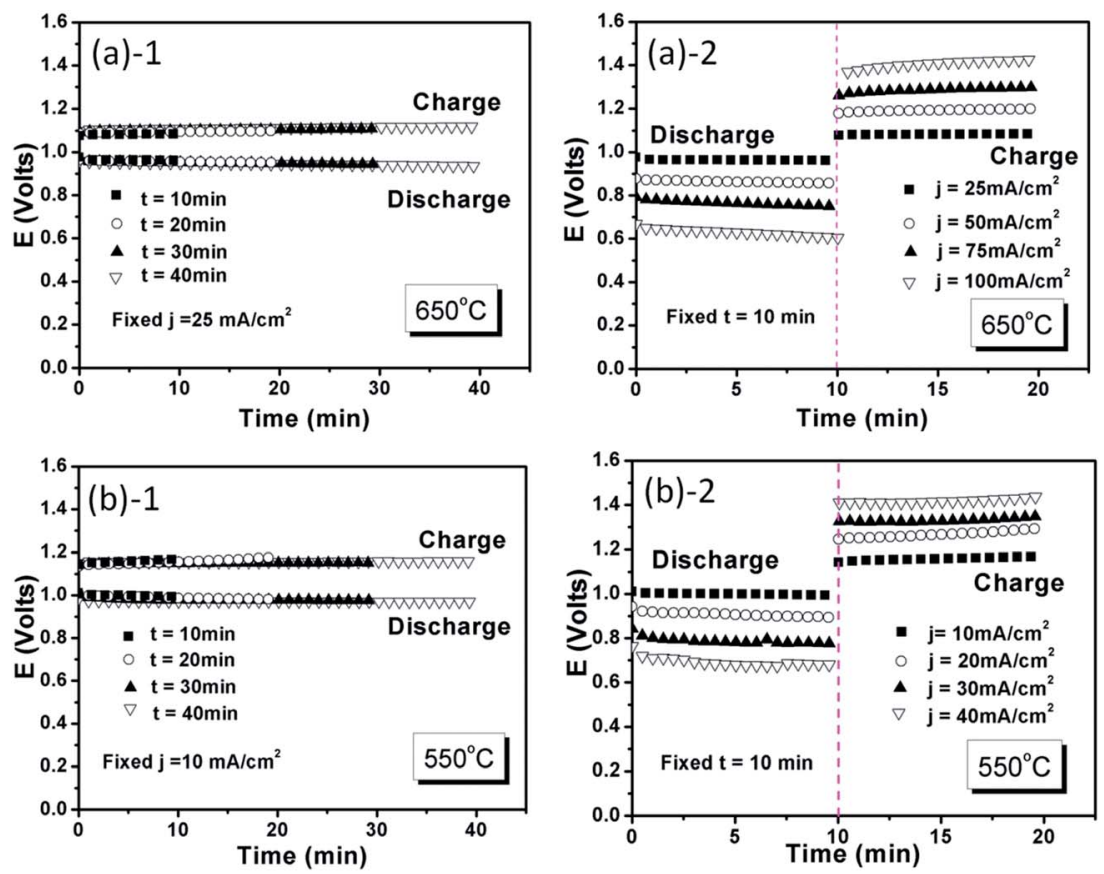

Fig. $3 E-t-j$ characteristics of the battery measured at $650{ }^{\circ} \mathrm{C}(\mathrm{a})$ and $550^{\circ} \mathrm{C}(\mathrm{b})$.

$102 \mathrm{~mA} \mathrm{~cm}{ }^{-2}$ at $550{ }^{\circ} \mathrm{C}$. These performances are typical of a thick-film LSGM based SOFC for the temperatures range. The operating current densities selected for the study are within $10 \%$ of the peak current densities to ensure meaningful cell voltage for practical operation.

\section{Battery characteristics}

The battery voltage as a function of operating current density and cycle duration is shown in Fig. 3 for 550 and $650{ }^{\circ} \mathrm{C}$. For either temperature, it is evident that the operating current density $(j)$ has a greater effect than cycle duration $(t)$. This is understandable according to the following simplified voltage equation for an electrochemical device:

$$
E=E_{\mathrm{N}} \pm i R
$$

where $E$ is the battery's terminal voltage; $E_{\mathrm{N}}$ is the Nernst potential; $i$ is the applied current and $R$ is the total resistance of
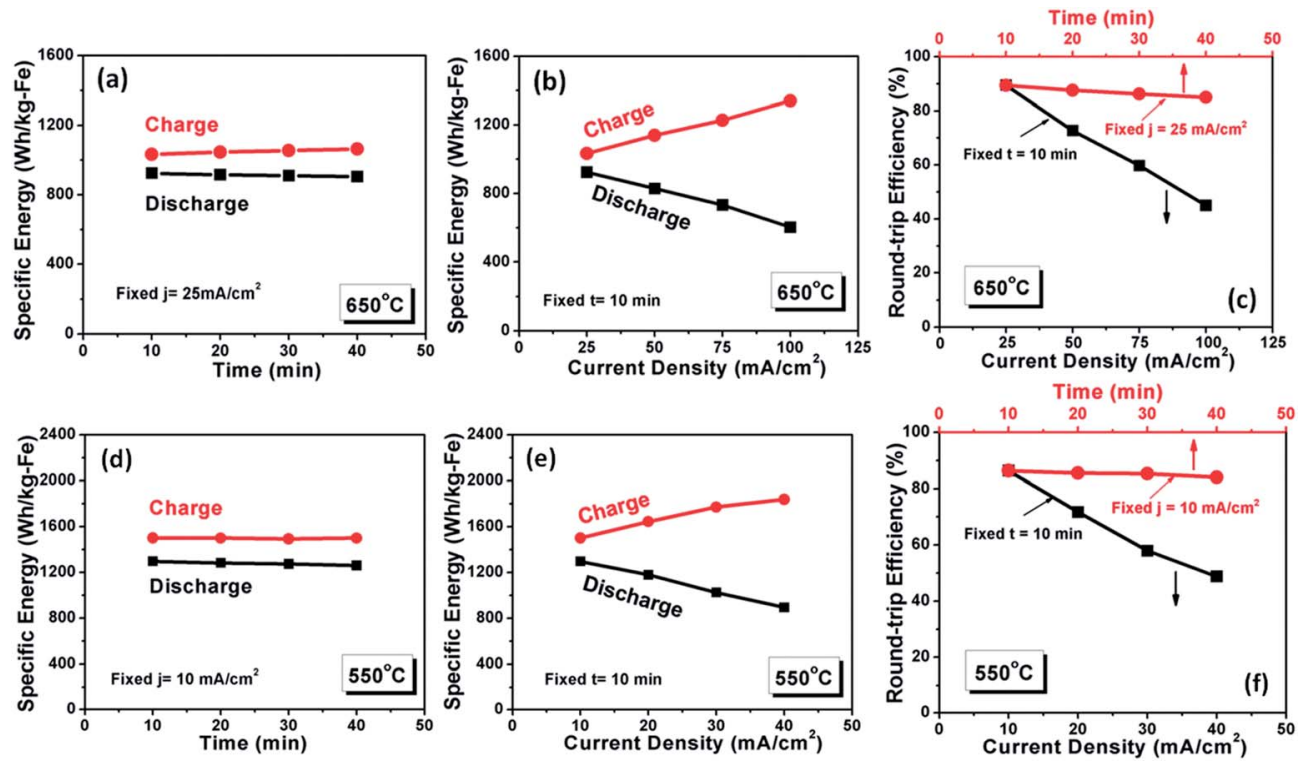

Fig. 4 (a) DSE/CSE - $t$ relationship with fixed $j$; (b) DSE/CSE-j relationship with fixed $t$; (c) RTE- $t-j$ relationship of the battery measured at $650{ }^{\circ} \mathrm{C}$; similar relationships measured at $550{ }^{\circ} \mathrm{C}$ are shown in (d)-(f), respectively. 
the battery. Evidently, higher $j$ leads to higher voltage loss $i R$, resulting in lower $E$ for the discharge and higher $E$ for the charge. There would be no effect from $t$ as long as the "aging" effect is negligible in the battery, which is particularly true for single-cycle study carried out herein.

Calculated from Fig. 3, the effects of $j$ and $t$ on discharge specific energy (DSE)/charge specific energy (CSE) and RTE are shown in Fig. 4(a)-(c) for $650{ }^{\circ} \mathrm{C}$ and (d)-(f) for $550{ }^{\circ} \mathrm{C}$, respectively. Each calculation was normalized to the actual $\mathrm{Fe}$ consumed by the oxygen flux provided by the RSOFC. At a fixed $j$ (Fig. 4(a) and (d)), both of the DSE and the CSE were stable over different cycle durations $(t)$. In contrast, at a fixed $t$ (Fig. 4(b) and (e)), DSE and CSE decrease as current density $j$ increases. The RTE is calculated by:

$$
\mathrm{RTE}=\mathrm{DSE} / \mathrm{CSE}
$$

It is evident from Fig. 4(c) and (f) that $j$ also has a greater impact on RTE than $t$, which is as expected.

The insensitivity of RTE to $t$ at a fixed $j=25 \mathrm{~mA} \mathrm{~cm}{ }^{-2}$ for $650{ }^{\circ} \mathrm{C}$ and $j=10 \mathrm{~mA} \mathrm{~cm}{ }^{-2}$ for $550{ }^{\circ} \mathrm{C}$ suggests good redox reversibility of the $\mathrm{Fe}-\mathrm{FeO}$ and $\mathrm{Fe}-\mathrm{F}_{3} \mathrm{O}_{4}$ redox couples, respectively, under these circumstances. The good reversibility observed is believed to largely benefit from the carbothermic reaction based synthesis yielding robust redox materials. These multi-variable comparisons further infer that operating a SOMARB under a relatively lower $j$ for longer cycle duration to achieve a required energy storage capacity is a preferred approach to maintaining a high RTE; this is also a strategy commonly used for lithium-ion batteries (LIBs). However, the rate capacity presented by SOMARB here is still close to one order of magnitude higher than LIBs. As the performance of RSOFC at reduced temperatures is being further improved by the use of thin-film electrolyte and nanostructured electrodes, the rate capacity as well as energy capacity of SOMARB can be further enhanced. Operation under $100 \mathrm{~mA} \mathrm{~cm}^{-2}$ at a reduced temperature, for example, is routinely achievable by an RSOFC.

\section{Conclusions}

A new class of all-ceramic solid-oxide iron-air redox batteries comprising of a reversible solid oxide fuel cell and multivalent metal/metal-oxide chemical bed has been recently demonstrated with great potential to overcome the challenges facing conventional liquid-based iron-air batteries. This study presented a systematic study of the new battery on the effects of operating current density and cycle duration on the specific energy and round trip efficiency at $650{ }^{\circ} \mathrm{C}$ and $550{ }^{\circ} \mathrm{C}$, under which two respective equilibrium redox couples of $\mathrm{Fe}-\mathrm{FeO}$ and $\mathrm{Fe}-\mathrm{Fe}_{3} \mathrm{O}_{4}$ predominate. The results explicitly showed that the current density is the most pronounced factor affecting the battery's performance, signifying the importance of retaining electrochemical performance of RSOFC for the new battery.

\section{References}

1 N. Xu, X. Li, X. Zhao, J. B. Goodenough and K. Huang, Energy Environ. Sci., 2011, 4, 4942-4946.

2 X. Zhao, N. Xu, X. Li, Y. Gong and K. Huang, RSC Adv., 2012, 2, 10163-10166.

3 X. Zhao, Y. Gong, X. Li, N. Xu and K. Huang, J. Electrochem. Soc., 2013, 160, A1241-A1247.

4 X. Zhao, X. Li, Y. Gong, N. Xu, K. Romito and K. Huang, Chem. Commun., 2013, 49, 5357-5359.

5 X. Zhao, Y. Gong, X. Li, N. Xu and K. Huang, J. Electrochem. Soc., 2013, 160, A1716-A1719.

6 M. Guo, X. Zhao, R. E. White and K. Huang, J. Electrochem. Soc., 2013, 160, A2085-A2092.

7 X. Zhao, Y. Gong, X. Li, N. Xu and K. Huang, J. Mater. Chem. A, 2013, 1, 14858-14861.

8 X. Zhao, X. Li, Y. Gong and K. Huang, Chem. Commun., 2014, 50, 623-625.

9 X. Zhao, N. Xu, X. Li, Y. Gong and K. Huang, ECS Trans., 2013, 50, 115-123.

10 X. Zhao, N. Xu, X. Li, Y. Gong and K. Huang, ECS Trans., 2013, 45, 113-121.

11 H. Landes and R. Reichenbacher, ECS Trans., 2013, 50, 4768.

12 A. Inoishi, Y. W. Ju, S. Ida and T. Ishihara, J. Power Sources, 2013, 229, 12-15.

13 A. Inoishi, S. Ida, S. Uratani, T. Okano and T. Ishihara, Phys. Chem. Chem. Phys., 2012, 14, 12818-12822.

14 A. Inoishi, Y. W. Ju, S. Ida and T. Ishihara, Chem. Commun., 2013, 49, 4691-4693.

15 A. Inoishi, S. Ida, S. Uratani, T. Okano and T. Ishihara, RSC Adv., 2013, 3, 3024-3030.

16 W. Drenckhahn, H. Greiner, M. Kuhne, H. Landes, A. Leonide, K. Litzinger, C. Lu, C. Schuh, J. Shull and T. Soller, ECS Trans., 2013, 50, 125-135.

17 H. Ohmori, S. Uratani and H. Iwai, J. Power Sources, 2012, 208, 383-390.

18 A. Inoishi, Y. Okamoto, Y. W. Ju, S. Ida and T. Ishihara, RSC Adv., 2013, 3, 8820-8825.

19 A. Inoishi, T. Ishihara, S. Ida, Y. W. Ju and T. Sakai, J. Mater. Chem. A, 2013, 1, 15212-15215. 